\title{
Molecular-level insights on uranium surface speciation in engineered barrier systems
}

\author{
AMRITA BHATTACHARYYA ${ }^{1,2}$, MIKE MASSEY ${ }^{2}$, \\ SYLVAIN GRANGEON ${ }^{3}$, CHRISTOPHE TOURNASSAT $^{4}$ \\ AND RUTH TINNACHER ${ }^{2}$ \\ ${ }^{1}$ Lawrence Berkeley National Laboratory \\ ${ }^{2}$ California State University East Bay \\ ${ }^{3}$ BRGM (French Geological Survey) \\ ${ }^{4}$ University of Orléans \\ Presenting Author: abhattacharyya@lbl.gov
}

In engineered barrier systems at future nuclear waste repositories, Na-montmorillonite is expected to limit contaminant mobility due to its low permeability and high sorption affinity for many radionuclides. A mechanistic understanding of radionuclide sorption reactions and their speciation on montmorillonite surfaces is needed in order to accurately predict contaminant transport based on surface complexation and reactive transport models.

In this study, we characterized uranium surface speciation on montmorillonite with the primary goal to examine the formation of U(VI)-carbonato surface complexes on Na-montmorillonite. This type of surface complex has been invoked in a number of previously-published U(VI) montmorillonite sorption models that do not specifically account for the "spill-over" effect, the influence of the electrostatic potential of basal surface sites on the potential of edge surface sites. However, our recently developed surface complexation model including the spill-over effect was able to predict $\mathrm{U}(\mathrm{VI})$ sorption onto Namontmorillonite over a wide range of $\mathrm{pH}$ and $\mathrm{pCO}_{2}$ conditions, without involving any U(VI)-carbonato surface complexes, and for our own and previously-published U(VI)-montmorillonite sorption data. Uranium(VI) surface speciation is, therefore, a key question.

We have characterized uranium surface speciation on montmorillonite by synchrotron-based XAS spectroscopy over a range of $\mathrm{pH}$ conditions $(\mathrm{pH} 5,7$ and 8), total $\mathrm{U}$ and $\mathrm{Ca}$ concentrations, and in the presence and absence of atmospheric $\mathrm{CO}_{2}$. Uranium $L_{3}$-edge XANES spectra were surprisingly similar, even though chemical solution conditions had been varied. We are now conducting detailed shell-by-shell fitting of $\mathrm{U} L_{3}$-edge EXAFS data with the goal to evaluate the relevance of uranyl-carbonato surface complexes further. Overall, the observed differences in the spectra are small and subtle. Furthermore, preliminary data suggest that uranyl is complexed with $\mathrm{Si}$, which is in agreement with previous studies. We are currently investigating the possible presence of U-C environments in our complexes at alkaline $\mathrm{pH}$ conditions, expected in engineered barrier systems. We are planning to present model fits which will allow us to better understand the prevalence and significance of uranyl-carbonato surface complexes for contaminant transport in uranyl-montmorillonite systems.

This research is funded through DOE's Nuclear Engineering 